\title{
Institutionalization of Quality Management Systems in the Central Registry of the Central Drug Control Laboratory, National Agency for Food and Drugs Administration and Control, Nigeria
}

\author{
A. A. Ekeigwe, aekeigwe@purdue.edu, K. Clase, kclase@purdue.edu, and S. Byrn, sbyrn@purdue.edu \\ Department of Biotechnology Innovation and Regulatory Sciences, Purdue University
}

\begin{abstract}
Quality management systems (QMS) are becoming a global paradigm especially in testing laboratories. A critical component of QMS in testing laboratories is the proper handling of in-coming samples to ensure that the integrity of such samples are not compromised in any way before the commencement of testing and assure the validity of the results received from testing units. The sample reception unit in the Central Registry of the Central Drug Control Laboratory (CDCL) of the National Agency of Food and Drug Administration and Control (NAFDAC), Nigeria, did not have a QMS in place. The methodology for instituting QMS involved reorganization of the unit, development of all working documents, training and retraining of all staff/team members, implementation of the new system and then conducting continuous monitoring and evaluation using predefined key performance indicators. The results clearly show that the implementation of a QMS in the Sample Reception unit of the Central Registry of the Central Drug Control Laboratory has greatly improved the overall effectiveness and efficiency of the unit. It has ensured that the integrity of incoming samples is not compromised before testing by the analytical units. This has led to increased trust and reliability of the test results and analytical reports produced by the Central Drug Control Laboratory of the National Agency for Food and Drugs Administration and Control of Nigeria.
\end{abstract}

\section{KEYWORDS}

Quality Management Systems (QMS), Key Performance Indicators (KPI), In-Coming Samples, Nonconformances, Standard Operating Procedures (SOP) 


\section{INTRODUCTION}

Quality management systems are becoming a global paradigm. All processes/organizations are implementing the principles of quality management systems to improve the quality and efficiency of their work output. Most testing laboratories are in the forefront of implementing QMS.

In most laboratories around the world, the handling of in-coming samples (e.g. biological specimen, chemical samples, raw materials or finished pharmaceutical products) all require appropriate care. These are to ensure that the integrity of the samples is not compromised in any way and assure the validity of the results received from testing units. Thus there is a general realization that the processes involved in the management of incoming samples are critical and should be under control if reliable results are to be obtained from testing.

To this end, the World Health Organization (WHO), the International Organization for Standards (ISO) and most National Drug Regulatory Authorities have guidelines for the proper handling of in-coming samples to laboratories.

A number of researches have been done in the area of handling biological specimens and chemicals of various types, however not much research has been done on the receipt of finished pharmaceutical products to pharmaceutical testing laboratories.

\section{Research Question/ Hypothesis}

Will the institutionalization of a quality management system in the Central Registry unit of the Central Drug Laboratory of NAFDAC improve the overall performance and quality of work of the unit?

My hypotheses is that the institutionalization of a quality management system in the Central Registry unit of the Central Drug Laboratory of NAFDAC will improve its overall performance and quality of work.

\section{Significance of the Problem}

The Central Drug Control Laboratory has the enormous responsibility of assuring that the populace uses only quality, safe and efficacious medicines by making pronouncements on the quality and effectiveness of medicines after appropriate quality control checks. These quality control checks must be done following approved international standards. Third world countries like Nigeria is battling with the growing menace of spuriously labeled and fake medicines that lead to treatment failures, drug resistant disease, and deaths among the populace. Nigeria, with a population of over 190 million people, has become a dumping ground for various manufacturers of medicinal product, especially from Asia. The populace must be protected from this menace by a strong and stringent regulatory body of which a quality control laboratory is part. Thus all analytical work done in the laboratory has impact on the overall healthcare system of the country. However its assessment process starts at the sample reception area of the central registry unit of the laboratory. If samples are not properly handled in accordance with international standards at this point, it invalidates all other processes of the laboratory ab-initio. It is an identified critical control point in the health care system of the country. It is therefore imperative that it must be structured to meet international standards for quality management systems.

Also for the laboratory to attain and retain World Health Organization pre-qualification status, it has to implement quality management system in this unit

\section{RESULTS OF LITERATURE SEARCH}

The literature search revealed that there is a dearth of scholarly work in the area of receipt, handling and storage of pharmaceutical products prior to analysis in testing laboratories.

However, a handful amount of work has been done in the area of handling and management of biological samples such as blood, urine etc. submitted to medical laboratories for testing.

There are research works and papers on how to implement quality management systems in laboratories in general. A number of researches have also been done to assess the impact of implementing quality management systems in different processes.

All the literature reviewed revealed that improper handling of incoming test samples has impact on the test results.

The article 'Effects of sample handling and storage on quantitative lipid analysis in human serum' written by Zikovic et al revealed that 'proper storage and handling of samples is paramount to retaining their informativeness' (Zivkovic et al., 2009). The researcher explored the effects of various storage and handling conditions such as freeze-thaw, extraction state, and storage temperatures, prior to the quantification of density-based lipoprotein fractionations. The same equipment was used to 
analyze the samples to eliminate any equipment sensitivity bias.

Studies by other investigators have corroborated this finding. Harsten et al showed that the way blood samples are handled significantly affected the results of blood gas analysis (Harsten, Berg, Inerot, \& Muth, 1988). Kozikwoski et al studied "the effect of room temperature storage on the stability of compounds stored in DMSO". The stability of approximately 7200 compounds stored as 20-mM DMSO solutions under ambient conditions was monitored for 1 year. The compound's integrity was measured by flow injection analysis using positive and negative electrospray ionization mass spectrometry. Each sample was assessed at the beginning of the study, after 12 months of storage, and at a randomized time point between the initial and final time points of the study. The study showed a gradual decrease in the integrity of the compounds (Kozikowski et al., 2003). The data obtained by Busch et al in their study of the impact of specimen handling and storage on detection of Hepatitis $C$ virus RNA further confirms that well controlled sample handling and storage processes are important to the quality of results obtained from the quantitative analysis of blood samples from patients who were positive on antiHCV supplemental blood test (Busch, Wilber, Johnson, Tobler, \& Evans, 1992).

There are however, clear guidelines on the proper handling of in-coming finished pharmaceutical products tested at pharmaceutical control laboratories. The guidelines reviewed were

1. World Health organization good practices for pharmaceutical quality control laboratories

2. ISO/IEC 17025 - General requirements for the competence of testing and calibration laboratories

Part 2, section 14 of the WHO guidelines gives clear directives for the proper handling of in-coming samples to pharmaceutical quality control laboratories. Samples received by the laboratory may be for compliance testing or for investigative testing. Samples for compliance testing include routine samples for control, samples suspected of not complying with the specifications or samples submitted in connection with a marketing authorization process (World Health Organization, 2010). A properly filled test request form should accompany all samples. Samples should be checked for any damages and matched with the information on the test request forms. All samples should be logged into a computerized system and given unique identification numbers. Samples should be stored in accordance with their recommended storage conditions while awaiting forwarding to testing units. There should be proper segregation of samples to avoid cross contaminations (World Health Organization, 2010)

Similarly, section 5.8 of the ISO/IEC 17025 - General requirements for the competence of testing and calibration laboratories expounded on the handling of test and calibration items. Section 5.8.1 states "The laboratory shall have procedures for the transportation, receipt, handling, protection, storage, retention and/or disposal of test and/or calibration items, including all provisions necessary to protect the integrity of the test or calibration item, and to protect the interests of the laboratory and the customer"(ISO, 2005). It also has requirements for unique identification of samples, segregation of samples to avoid cross contamination and maintenance of adequate records.

These guidelines underscore the importance of appropriate handling of all incoming samples. Any discrepancies at this point will affect all the validity of the test results. Implementation of these guidelines is part of the institutionalization of quality management systems in a drug-testing laboratory.

It is generally agreed in the literature that the implementation of quality management systems in any organization or process will lead to an improvement in the operational systems of that organization. The article "The Impact of ISO 9000 Quality Management Systems on Manufacturing" attests to this. The research showed a significant improvement in the performance of certified companies (i.e. companies that have implemented ISO 9000 Quality Management Systems) over those that are not certified (Tufan, 2007). 106 small and medium sized companies were examined of which 79 of them had implemented ISO 9000 standards. Melnyk Steven et al, in their study of assessing the impact of environmental management systems on corporate and environmental performance also supports this theory (Melnyk, Sroufe, \& Calantone, 2003). Their results shows that firms that have EMS and ISO 14001 certification have greater impact on performance than firms who do not. Hongyi in his research paper showed that there is a relationship between the implementation of TQM and ISO standards and an improvement in performance of the organization.(Hongyi, 2000). Other reseachers that support this idea are Kaynak Hale (Hale, 2003) and Rao et al (Rao, Ragu-Nathan, \& Solis, 1997). Konovalova and Popova concluded that implementation of quality management systems in drug testing laboratories leads to the production of 
quality results in time frames agreed with the clients using accepted testing methods. This in turn leads to customer satisfaction (Konovalova \& Popova, 2010).

The literatures revealed that the successful implementation of any quality management system is dependent on the framework of the implementation process. It is important to formulate a sound implementation framework prior to the embarking on such a change. It will be important to take into cognizance the systems on ground in the organization and construct a stepwise implementation framework that will have positive impact on the system. (Yusof \& Aspinwall, 2010). This thought is supported by studies conducted by Andiric and Massambu. They studied the improvement of laboratory quality in Tanzania. The study showed that the improvement plan consisted of formalized hands-on training under the Strengthening Laboratory Management Toward Accreditation program (SLMTA) that teaches the tasks and skills of laboratory management and provides the tools for implementation of best laboratory practice. (Andiric \& Massambu, 2015). Other researchers that support this thought are Yao et al (Yao et al., 2010). Groucher et al, in their peer reviewed article - "A process approach to ISO/IEC 17025 in the implementation of a quality management system in testing laboratories", showed that implementation of quality management systems require a stepwise approach (Grochau \& ten Caten, 2012).

\section{METHOD \\ Design And Implementation}

It is a quantitative type of research using a retrospective-prospective study design. The following data sets will be collected-

- Retrospective data- this is a quantitative secondary type of data that will be acquired from the audit reports before the intervention. We will extract the number and type of non-conformances of the unit.

- Prospective data - it is a quantitative data. There are 2 sets of data that will be collected viz-

- Measurement of KPIs

- Number of non-conformances after the implementation of quality systems in the unit

To implement quality systems in the sample reception area of the central registry unit, the following were done:

- Restructuring of the unit to perform all its expected functions (Organograms, Job descriptions)

- Development of all relevant quality documents (SOPs, Work Instructions, etc)

- Training of all staff

- Test run of the new SOPs

- Review of the SOPs

- Full deployment of the new system

- Monthly evaluation of the new system using KPIs (clearly defined KPIs will be developed)

- Periodic self-audits of the unit

- Scheduled audits by the Quality Assurance Manager of the Central Drug Control Laboratory

- Other audits by external bodies e.g WHO 


\section{Monitoring}

The implementation of quality management systems in the Sample reception unit was monitored using clearly defined KPIs outlined below

1. $95 \%$ compliance in inputting all in-coming samples into the Electronic laboratory system of the Central Drug Control Laboratory within 72 hours

2. $95 \%$ error free (right-first-time) entries of sample data logged into the Electronic laboratory system of the Central Drug Control Laboratory

3. $70 \%$ reduction in the severity of nonconformances from the Sample Reception unit

4. The environment of the storage area of incoming samples should be monitored twice daily

5. The percentage of samples damaged during handling at the sample reception area of the Central Registry should be less than $1 \%$ of the total number of samples received.

\section{RESULTS}

Statistical methods were used to analyze and present the data obtained from monitoring the implementation of quality management systems. The number and types of non-conformances observed from the various audits, before and after the implementation of the Quality Management System were compared.

The KPIs measured were charted to determine whether there is continuous improvement in the system. The findings are presented below.

\section{Percentage of Samples Inputted into the System within $72 \mathrm{hrs}$}

This parameter, or KPI, helps to measure the efficiency of the sample reception process, that is, how fast the unit is able to process samples and input their details on the Electronic lab. From the chart, it is clear that there was an initial increase in efficiency between the months of May (37\%) to August (79\%) and then a sharp decline in September $(12.9 \%)$, followed by a moderate improvement in October (25.6\%). The set criterion for this $\mathrm{KPI}$ is $95 \%$ compliance in inputting all in- coming samples into the Electronic laboratory system of the Central Drug Control Laboratory within 72 hours. This criterion was not met

Table 1- Percentage of Samples inputted into the system within $72 \mathrm{hrs}$

\begin{tabular}{cc}
\hline Month & $\begin{array}{l}\text { Percentage of Samples Inputted } \\
\text { Into The System within 72hours }\end{array}$ \\
\hline May & 37 \\
June & 45 \\
July & 68 \\
August & 79 \\
September & 12.9 \\
October & 25.6 \\
\hline
\end{tabular}

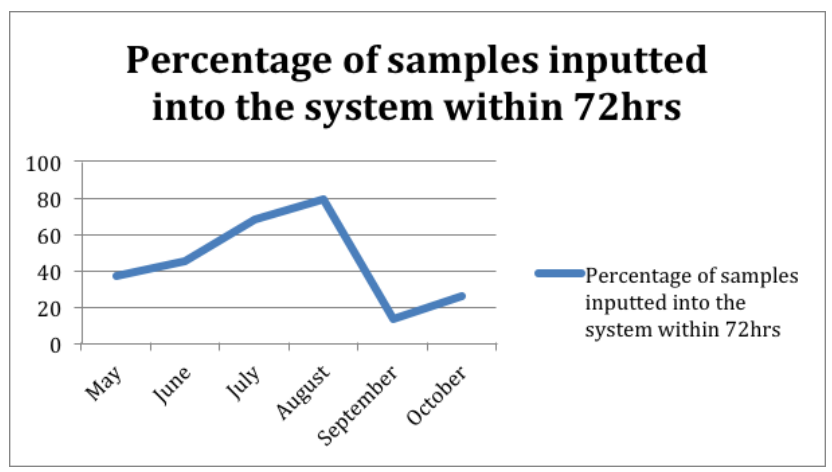

Figure 1- Percentage of Samples inputted into the System Within $72 \mathrm{hrs}$.

\section{Percentage of Error Free (Right-First- Time) Entries.}

This KPI seeks to measure the effectiveness of the unit in handling the sample receipt process.

The chart shows a steady increase in the percentage of error free entries. At the beginning of the measurement of this $\mathrm{KPI}$, there was a $90 \%$ error free entry. However as of October, we had a $98.14 \%$ error free entry. The set criterion for this KPI is $95 \%$ error free entries of sample data logged into the Electronic laboratory system of the Central Drug Control Laboratory. The unit exceeded the set criterion. This implies that the unit is becoming more effective in handling the sample receipt process. 
Table 2- Percentage of Error Free Entries

\begin{tabular}{cc}
\hline Month & Percentage of Error Free Entries \\
\hline July & 90 \\
August & 93.88 \\
September & 96.36 \\
October & 98.14 \\
\hline
\end{tabular}

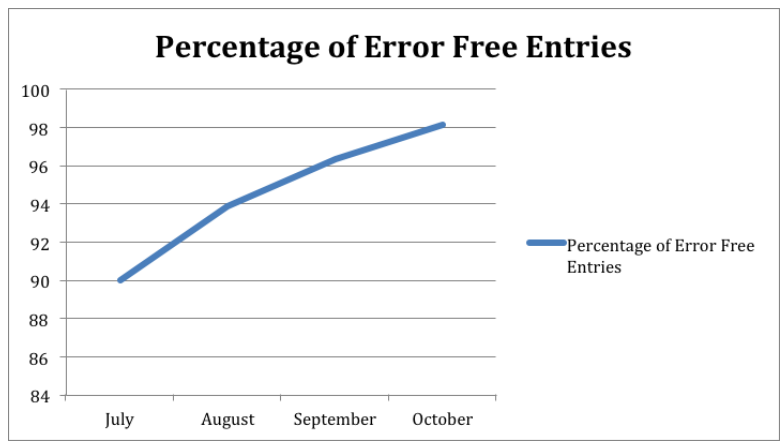

Figure 2 Percentage of Error Free Entries.

\section{Number and Type of Non-Conformances}

This parameter is one of the true tests of the successful implementation of quality management systems. Konovalova and Popova stated that one of the main sources of information for the evaluation of the effectiveness of the implementation of quality management systems is reports from internal and external audits. Audits usually highlight the areas where improvement is necessary and gives an indication of whether a system is improving (Konovalova \& Popova, 2010).

The chart shows that the total number of nonconformances has steadily decreased between the WHO Assessment in 2006 and the WHO Peer audit in 2015 . The audit of 2006 revealed 8 nonconformances while that of 2015 revealed only 3 non-conformances in the sample reception unit. Also of note is that there is an $87.5 \%$ reduction in the number of major non-conformances between 2006 and 2015. The set criterion for this KPI was a 70\% reduction in the severity of (i.e major) nonconformances. This singular KPI gives a clear indication of improvement in the performance of the sample receipt process.
Table 3- Number and Type of Non-Conformances

\begin{tabular}{lccc} 
Type of Audit & \multicolumn{3}{c}{ Number of Non-Conformances } \\
\cline { 2 - 3 } & Major & Minor & Total \\
WHO & 8 & 0 & 8 \\
$\begin{array}{c}\text { Assessment } \\
2006\end{array}$ & & & \\
Internal Audit & 5 & 2 & 7 \\
by QA March & & & \\
2015 & & & 3 \\
WHO Peer & 1 & 2 & \\
Audit August & & & \\
2015 & &
\end{tabular}

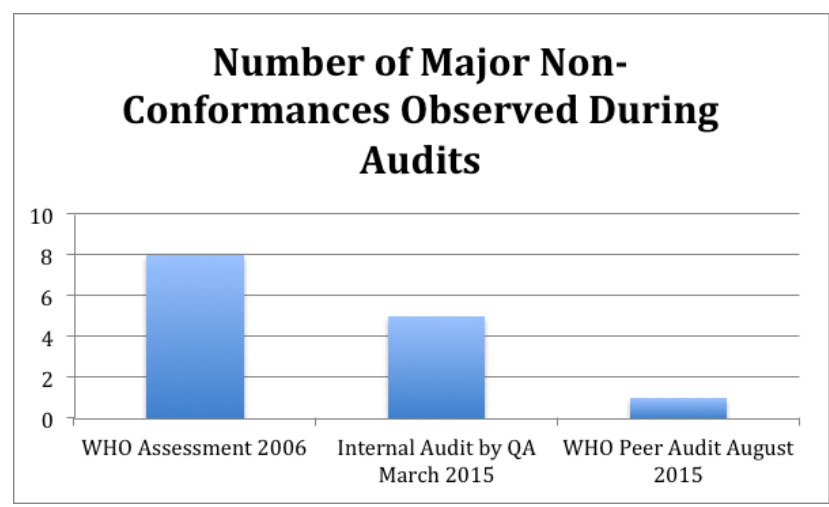

Figure 3a Number of Major Non-Conformances observed During Audits.

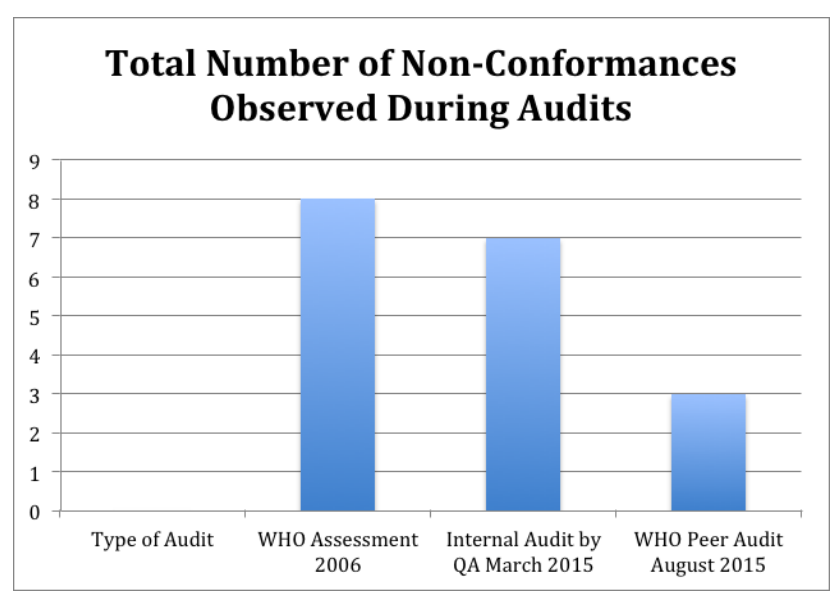

Figure $\mathbf{3 b}$ Number of Major Non-Conformances observed During Audits. 


\section{Percentage of samples damaged during handling}

This KPI is a measure of how carefully samples are handled as they are received into the laboratory. The chart indicates that there has been a steady decrease in the percentage of samples damaged during the sample receipt process. In May, when the monitoring began, $1.16 \%$ of the total numbers of samples received for that month were damaged during handling. However by October, it was a 0\% record of damaged samples. This is a 100\% improvement in this KPI. The set criterion for this KPI is the percentage of samples damaged during handling at the sample reception area of the Central Registry should be less than $1 \%$ of the total number of samples received. The unit has thus exceeded this set criterion

Table 4- Percentage of Samples Damaged During Handling

\begin{tabular}{cc}
\hline Month & $\begin{array}{c}\text { Percentage of Samples Damaged } \\
\text { During Handling }\end{array}$ \\
\hline May & 1.16 \\
June & 0.88 \\
July & 0.33 \\
August & 0.47 \\
September & 0.49 \\
October & 0 \\
\hline
\end{tabular}

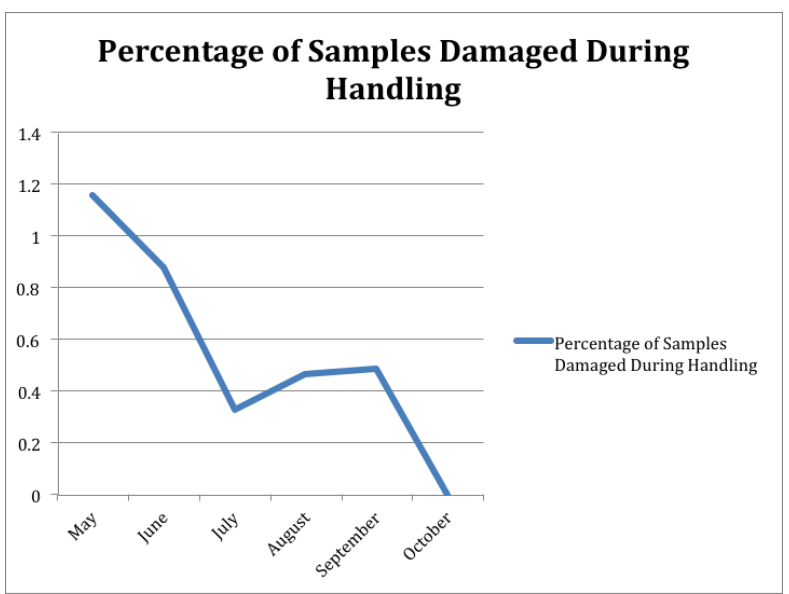

Figure 4 Percentage of Samples damaged During Handling

\section{DISCUSSION}

The findings presented above clearly show that there has been a general improvement in the performance of the Sample Reception unit. Almost all key performance indicators monitored during and after the implementation of the quality management system showed improvement. The most indicative $\mathrm{KPI}$ is the number and type of non-conformances observed during audits. The most recent audit of the sample reception unit, by WHO revealed only one major non-conformance and 2 minor nonconformances. This is an $87.5 \%$ improvement over the first audit in 2006 where eight major nonconformances were observed.

A 98.14\% error-free entries were achieved after the implementation of QMS as opposed to the $90 \%$ error-free entries observed before the implementation of QMS. The percentage of samples damaged during handling steadily declined to $0 \%$. The environmental conditions of the storage location for incoming samples were closely monitored to ensure that the integrity of incoming samples are not compromised.

However, the indicator for the monitoring of the efficiency of the unit, that is, the number of samples inputted within 72 hours, did not show consistent improvement. This indicator was initially improving from $37 \%$ in May to $79 \%$ in August and then a sharp decline to $12.9 \%$ in September. Investigations into this observation showed that there are major deficiencies in the sample reception unit that has to be addressed. The first is that the unit does not have enough qualified and trained staff. The unit relies heavily on temporary staff to help it in its functions. Thus in the months where there was a sharp decline in the speed with which samples were inputted into the system, it was found that the unit did not have enough trained personnel to handle all its function. The second issue was that the unit did not have enough tools (e.g. high speed computers) to carry out its functions.

These findings clearly show that the implementation of a quality management system in the Sample Reception unit of the Central Registry of the Central Drug Control Laboratory has greatly improved the overall effectiveness and efficiency of the unit. It has ensured that the integrity of incoming samples are not compromised before testing by the analytical units. This has led to increased trust and reliability of the test results and analytical reports produced by the Central Drug Control Laboratory of the National Agency for Food and Drugs Administration and Control. 
It can therefore be concluded that implementing QMS in the sample reception unit of a pharmaceutical control laboratories will lead to improved performance, reliable and accurate test results.

It is suggested that the monitoring of these KPI should be continued. The scope of monitoring may be expanded to include more KPIs that will involve the whole Central Registry section and not just the sample reception unit

\section{ACKNOWLEDEMENTS}

The completion of this directed project could not have been possible without the participation and assistance of so many people whose names may not all be enumerated. Their contributions are sincerely appreciated and gratefully acknowledged. However, I would like to express my deep appreciation and indebtedness particularly to the following:

Sister Zita, Professor Steve Bryn, Professor Joe Fortunak, Professor Kari Clase, Professors Janet and Gary Fourman, Professor Louis Yu, Professor Ralph Johnson, Professor Fran Eckenrode, and Dr. Amtav for their lectures, endless support, kind and understanding spirit during this Master's programme and project.

The sponsors of this program, UNIDO and Merck Foundation.

To all relatives, friends and others who in one way or another shared their support, morally, financially and physically, thank you.

Above all, to the Great Almighty, the author of knowledge and wisdom, for His countless love.

I thank you.

\section{REFERENCES}

Andiric, L. R., \& Massambu, C. G. (2015). Laboratory Quality Improvement in Tanzania. doi:10.1309/AJCPAB4A6WWPYIEN

Busch, M. P., Wilber, J. C., Johnson, P., Tobler, L., \& Evans, C. S. (1992). Impact of specimen handling and storage on detection of hepatitis $C$ virus RNA. Transfusion, 32(5), 420-425. doi:10.1046/j.15372995.1992.32592327714.x

Grochau, I., \& ten Caten, C. (2012). A process approach to ISO/IEC 17025 in the implementation of a quality management system in testing laboratories. Accreditation and Quality Assurance, 17(5), 519-527. doi:10.1007/s00769-012-0905-3

Hale, K. (2003). The relationship between total quality management practices and their effects on firm performance. 21(4), 405-435. doi:10.1016/S0272-6963(03)00004-4

Harsten, A., Berg, B., Inerot, S., \& Muth, L. (1988). Importance of correct handling of samples for the results of blood gas analysis. Acta

Anaesthesiologica Scandinavica, 32(5), 365-368. doi:10.1111/j.1399-6576.1988.tb02746.x

Hongyi, S. (2000). Total quality management, ISO 9000 certification and performance improvement. International Journal of Quality \&amp; Reliability Management, 17(2), 168-179. doi:10.1108/02656710010304573

ISO. (2005). ISO/IEC 17025 General requirements for the competence of testing and calibration laboratories. In. Switzerland: ISO.

Konovalova, N. M., \& Popova, A. V. (2010). Quality management system in testing laboratory. Inorganic Materials, 46(15), 1710-1711.

Kozikowski, B. A., Burt, T. M., Tirey, D. A., Williams, L. E., Kuzmak, B. R., Stanton, D. T., ... Nelson, S. L. (2003). The Effect of Room-Temperature Storage on the Stability of Compounds in DMSO. doi:10.1177/1087057103252617

Melnyk, S. A., Sroufe, R. P., \& Calantone, R. (2003). Assessing the impact of environmental management systems on corporate and environmental performance. Journal of Operations Management, 21(3), 329-351.

doi:http://dx.doi.org/10.1016/S02726963(02)00109-2

Rao, S. S., Ragu-Nathan, T. S., \& Solis, L. E. (1997). Does ISO 9000 have an effect on quality management practices? An international empirical study. Total Quality Management, 8(6), 335-346. doi:10.1080/0954412979352

Tufan, K. (2007). The impact of ISO 9000 quality management systems on manufacturing. 186(Issues 1-3), 207-213. doi:10.1016/j.jmatprotec.2006.12.034

World Health Organization. (2010). WHO good practices for pharmaceutical quality control laboratories Retrieved from

Yao, K., McKinney, B., Murphy, A., Rotz, P., Wafula, W., Sendagire, H., . . Nkengasong, J. N. (2010). Improving Quality Management Systems of Laboratories in Developing Countries An Innovative 
Training Approach to Accelerate Laboratory Accreditation. American journal of clinical pathology, 134(3), 401-409.

Yusof, S. R. M., \& Aspinwall, E. (2010). Total quality management implementation frameworks:

Comparison and review.

http://dx.doi.org/10.1080/0954412006801. doi:Total Quality Management, Vol. 11, No. 3, May 2000, pp. 281-294

Zivkovic, A. M., Wiest, M. M., Thao, N. U., Davis, R., Watkins, S. M., \& German, J. B. (2009). Effects of sample handling and storage on quantitative lipid analysis in human serum. metabolomics, volume 5 (issue 4), 507-516. 